ment in mortality was especially noticeable in severe first attacks and in severe episodes in patients over 60 years of age. A review of the 140 patients who survived without operation during their attacks showed that over one-third subsequently required surgical treatment either as an elective procedure or because of further attacks. Perforation of the colon was found in 21 cases (with a mortality of $28.6 \%$ ). Acute colonic dilatation was observed in 28 instances; 27 were treated by emergency colectomy and perforation had occurred in eleven cases. The mortality of these operations was $18.5 \%$.

The authors point out that their results have the disadvantage of not being carried out with the rigid discipline of a controlled prospective trial, and some of the improvement that they record might in theory be due to some change in the character of the cases with severe colitis during the period under review. However, the excellence of the results now being obtained with early surgery in patients with severe colitis and its complications would cast serious ethical doubts on a prospective trial of early against late intervention.

\section{Diabetes and Menstruation}

The concentration of several constituents of the plasma varies with the phase of the menstrual cycle. Reviewing the subject

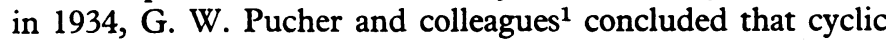
variations in the level of blood sugar must be regarded as uncertain. That comment remained true until recently. Now several studies reported over the past three years have shown fairly convincingly that, while the patient's tolerance of oral glucose is subject to some cyclic variation, ${ }^{23}$ tolerance of intravenous glucose does not vary. ${ }^{4-6}$ It appears that oral glucose tolerance is greatest during the period of menstrual flow and worsens as the cycle progresses. ${ }^{2}$ 7-9

As the administration of oestrogens ${ }^{10}$ but not of progestogens ${ }^{6}$ worsens oral glucose tolerance, it is tempting to correlate the changes in glucose tolerance with those of endogenous production of oestrogen during the cycle. ${ }^{2}$ I. Macdonald and J. N. Crossley ${ }^{3}$ suggest that the increase in the rate of gastric emptying which occurs in mid-cycle may be responsible for the apparent change in glucose tolerance. If this is correct, it might also explain the lack of cyclic variation in intravenous glucose tolerance.

Whereas in non-diabetics oral glucose tolerance is greatest at the time of menstruation, in established diabetics hyperglycaemia may be greater and ketosis may be precipitated at or about the menstrual period. ${ }^{11-13}$ Sometimes the swing is so great that the diabetes becomes virtually or actually un-

1 Pucher, G. W., Griffith, F. R., Brownell, K. A., Klein, J. D., and Cramer, M. E., Fournal of Nutrition, 1934, 7, 169

2 Jarrett, R. J., and Graver, H. J., British Medical fournal, 1968, 2, 528.

${ }^{3}$ Macdonald, I., and Crossley, J. N., Diabetes, 1970, 19, 450.

- Spellacy, W. N., Carlson, K. L., and Schade, S. L., American fournal of Obstetrics and Gynecology, 1967, 99, 382.

s Pyöralä, K., Pyöralä, T., and Lampinen, V., Lancet, 1967, 2, 776.
- Larsson-Cohn, U., Tengström, B., and Wide, L., Acta Endocrinologica (Kobenhavn), 1969, 62, 242.

?key, R., and Robb, E. I., Journal of Biological Chemistry, 1925, 65, 165.

- Garafi, G., and Ruggeri, G., Monitore Ostetrico-Ginecologico di Endocrinologia e Metabolismo, 1933, 5, 557.

Asinelli, C., and Casassa, P.M., Archivio per le Scienze Mediche, 1937, 64, 431 .

10 Buchler, D., and Warren, J. C., American fournal of Obstetrics and Gynecology, 1966, 95, 479 .

${ }^{11}$ Harrop, G. A., jun., and Mosenthal, H. O., Bulletin of the Johns Hopkins Hospital, 1918, 29, 161.

12 Hubble, D., British Medical fournal, 1954, 2, 1022.

13 Greene, R., Metabolism, $1958,7,90$

14 Cramer, H. I., Canadian Medical Association fournal, 1942, 47, 51.

15 Sandström, B., Nordisk Medicin, 1969, 81, 727.

16 Louis, L. H., Metabolism, 1969, 18, 545. controllable. Fortunately these extreme cases are rare, but lesser variation in the level of the blood sugar is probably fairly common. Thus H. I. Cramer ${ }^{14}$ analysed all patients between the ages of 14 and 45 admitted to hospital because of diabetic ketoacidosis from 1922 to 1940 . Of 96 cases $73 \%$ were women, and of 36 women previously treated and without infection nearly half were admitted during menstruation. A recent report ${ }^{15}$ describes a patient who went into diabetic coma or precoma with every menstrual period during the course of a year. This remarkable and distressing cycle was brought to an end by the sequential administration of ethinyloestradiol and dydrogesterone. A patient of R. Greene's who had similar but less severe phasic resistance to insulin responded to the administration of fluorohydrocortisone during the luteal phase of the cycle. ${ }^{13}$

It seems unlikely that growth hormone or the ovarian or adrenal steroids play any part in this phasic resistance to insulin, for a similar resistance might then be expected to accompany diabetic pregnancy. It is more likely that ovarian or adrenal steroids or their analogues inhibit the release of some pituitary substance other than growth hormone. Diabetogenic polypeptides have been isolated from the pituitary glands of several species of animals and from the urine of some patients with diabetes, ${ }^{16}$ but whether they are connected with the diabetic state is not yet known.

\section{Cystic Degeneration of the Popliteal Artery}

Some 40 cases of cystic adventitial disease of the popliteal artery have been reported. The first case was described by B. Ejrup and I. Hiertonn in $1954^{1}$ and was included in a second paper recording four cases. ${ }^{2}$ The patients complained of intermittent claudication, and the main lesion was found to be a cyst lying within the adventitial layer of the popliteal artery. Further reports followed, including a recent one from S. J. A. Powis and colleagues. ${ }^{3}$

The incidence of this uncommon condition has been estimated in two different centres ${ }^{5}$ as about 1 in 1,200 patients presenting with intermittent claudication. It occurs mainly in males, only three cases having been described in women. The age of the patients has ranged from 11 to 61 years, with a mean of 36 in males. Probably some cases have not been reported and others have not been recognized, but because treatment gives successful results a correct diagnosis is important.

The aetiology is obscure. It has been regarded as a mucinous degeneration in the adventitial layer of the artery not associated with atherosclerosis. Despite a lack of evidence that it is Ejrup, B., and Hiertonn, T., Acta Chirurgica Scandinavica, 1954, 108, 217.
2 Hiertonn, T., Lindberg, K., and Rob, C., British fournal of Surgery, 1957, $44,348$.

3 Powis, S. J. A., Morrissey, D. M., and Jones, E. L., Surgery, 1970, 67, 891.

Lewis, G. J. T., Douglas, D. M., Reid, W., and Watt, J. K., British Medical fournal, 1967, 3, 411 .

5 Hamming, J. J., and Vink, M., fournal of Cardiovascular Surgery, 1965, 6,516 .

6 Atkins, H. J. B., and Key, J. A., British Fournal of Surgery, 1947, 34, 426.

Parkes, A., fournal of Bone and foint Surgery, 1961, 43B, 784

Backstrom, C. G., Linell, F., and Ostberg, G., Acta Chirurgica Scandinavica, 1965, 129, 447.

- Ishikawa, K., Mishima, Y. and Kobayashi, S., Angiology, 1961, 12, 357.

10 Albertazzi, V. J., Elliott, T. E., and Kennedy, J. A., Angiology, 1969,

$20,119$.
11 Harris, J. D., and Jepson, R. P., Australian and New Zealand fournal of Surgery, 1965, 34, 265 .

12 Haid, S. P., Conn, J., and Bergan, J. J., paper presented at the International Cardiological Society, North American Chapter, 1970. 